\title{
Kinetic analysis of thermal degradation of NR/EPDM blends with maleic anhydride as compatibilizer: The effect of the reactive accelerators
}

\author{
Hesty Eka Mayasari*, Arum Yuniari \\ Center for Leather, Rubber, and Plastics, Ministry of Industry, J1. Sokonandi No. 9 Yogyakarta, 55166, Indonesia \\ *Corresponding author. Tel.: +62 274 512929, 563939, Fax.: +62 274563655 \\ E-mail: hestyeka@kemenperin.go.id
}

Received: 29 August 2017 Revised: 29 October 2017 Accepted: 01 November 2017

\begin{abstract}
Thermal characteristic is important to determine the thermal resistance of a polymer. In this work, the thermal characteristics of the NR/EPDM blends was investigated to study the storage and application condition of the blends. The NR/EPDM blends were prepared in the two-roll mill by using MAH as a compatibilizer with several types of accelerators, i.e., MBTS from thiazole group, the combination of MBTS and TMTD from thiuram group, and TBBS from sulphenamide group. This research used the thermogravimetric method with the heating rate of 10,15 , and $20^{\circ} \mathrm{C} / \mathrm{min}$. The kinetic parameters are calculated by using Coats-Redfern equation. The degradation of NR/EPDM blends occurs in two stages (first stage at $220-420{ }^{\circ} \mathrm{C}$ and second stage at $420-520{ }^{\circ} \mathrm{C}$ ). Combination of MBTS and TMTD give higher energy activation $(112.236 \mathrm{~kJ} / \mathrm{mol})$, followed by MBTS-blend $(111.999 \mathrm{~kJ} / \mathrm{mol})$, and TBBS-blend $(110.856 \mathrm{~kJ} / \mathrm{mol})$. Combination of MBTS and TMTD accelerator with MAH as the compatibilizer is the proper choice for NR/EPDM blends to get a good thermal stability.
\end{abstract}

Keywords: NR/EPDM, MAH, thermal degradation, accelerator.

\section{INTRODUCTION}

The polymeric material, when exposed to heat, will be oxidized. This thermal resistance is different for each polymer, depending on the type, storage, and conditions of application. Thermal characteristics need to be studied to determine the ability of a material to be used before it is degraded. Degradation is the breaking of bonds in the polymer due to free radicals, thereby reducing the polymer's properties. Thermogravimetry is the most commonly used method for studying the thermal characteristics of the materials (Komalan et al., 2008; Nabil et al., 2014).

Currently, there are a lot of research on blending between two or more types of rubber to improve the properties of the final product (Samarz et al., 2013; Nabil et al., 2014). EPDM is a saturated rubber that has good ozone resistance and good chemical resistance (Nabil et al., 2013). Natural rubber is an unsaturated rubber and it easily being deteriorated by ozone, but it has good mechanical properties. Blending NR/EPDM can improve the mechanical properties of the product. It is widely used in the automotive industry (Sahakaro et al., 2008). However, due to the different properties of NR and EPDM, i.e., saturation, polarity, filler affinity, and solubility, the NR/EPDM blend produces a blend with poor mechanical properties because it is an incompatible blend (Sahakaro et al., 2008; Sae-oui \& Sirisinha, 2007). The compatibilizer is needed to make NR/EPDM blend become more compatible. In this study, maleic anhydride (MAH) was used as a compatibilizer, as has been done by some previous researchers (Pasbakhsh et al., 2009; Tavakoli et al., 2011; Ismail \& Mathialagan, 2012).

In the manufacture of rubber materials, additives are needed to improve the product's properties. Accelerator is one of the additives that accelerate the vulcanization process. This type of accelerator may affect the mechanical properties, processability, and thermal resistance of the material (Sae-oui \& Sirisinha, 2007; Nabil et al., 2014). This study used MBTS (2,2dithiobis(benzothiazole)), combination of MBTS and TMTD (tetramethyl thiuram disulfide), and 
TBBS (n-tert-butyl-2-benzothiazolesulfenamide) as the accelerators. MBTS is an accelerator from thiazole group, TMTD from thiuram group, and TBBS from sulfenamides group.

Research on the blending of NR/EPDM has been widely practiced. Sae-oui \& Sirisinha (2007) studied the mechanical properties of a blending of NR/EPDM with several accelerators, Sahakaro et al. (2008) studied the blending technique of NR/ EPDM blend. Alipour et al. (2011) studied the morphology and properties of NR/EPDM with organoclay, Nabil et al. (2013) studied the morphology, compounding, and mechanical properties of NR/R-EPDM, and Nabil et al. (2014) studied the thermal stability of NR/EPDM with variations of vulcanization and accelerator systems. However, research on the effect of accelerators on the NR/ EPDM thermal characteristics has not been widely practiced, especially for blending with $\mathrm{MAH}$ as the compatibilizer. The blending of NR/EPDM with MAH as the compatibilizer was studied previously (Mayasari et al., 2017). However, it was focused on the cure characteristics and mechanical properties. To extend our work, the characteristics and kinetics degradation of the NR/EPDM blend using MAH as compatibilizers with several types of accelerators was carried out. The thermogravimetric method was done to study the degradation of NR/EPDM blends when the heat is applied. It is important to know the the storage and application condition of the blends.

\section{MATERIALS AND METHODS \\ Materials}

EPDM/NR blends were made with the formulations described in previous study by Mayasari et al., (2017) with EPDM (Keltan 4551 A), NR (SIR 20) by PTPN IX, carbon black (CB) N220 (Korea), paraffin wax (Antilux 654 A), TMQ (Kemai), paraffinic oil (Indrasari), $\mathrm{ZnO}$ (Indoxide), stearic acid (Aflux 42M), MBTS and TBBS (Shandong Sianxian), TMTD (Starchem), Sulphur (Miwon), MAH (Justus), and dicumyl peroxide (DCP) (Sigma Aldrich).

\section{Methods}

This study used the two-roll mill for compounding, hydraulic press machine for vulcanization, rheometer Gotech 3000A for studying the compound's rheology, and Shimadzu DTG-60H for thermogravimetric analysis.

The NR/EPDM blends were prepared by methods and formulations according to prior study (Mayasari et al., 2017). The formulations of NR/ EPDM blends are shown in Table 1 and Table 2. Vulcanization of EPDM/NR using a two-roll mill, and vulcanized in a hydraulic press at $160^{\circ} \mathrm{C}$ with a pressure of $150 \mathrm{~kg} / \mathrm{cm}^{2}$ with time-based on the rheometer.

\section{Thermal degradation}

The thermogravimetric analysis was done using Shimadzu DTG-60H in oxygen with a flow rate of $30 \mathrm{ml} / \mathrm{min}$ at $30-600^{\circ} \mathrm{C}$. Around $5-8 \mathrm{mg}$ NR/EPDM powder sample was heated with a heating rate of 10,15 , and $20^{\circ} \mathrm{C} / \mathrm{min}$ using an alumina pan.

\section{Kinetics analysis}

The kinetic analysis of the degradation process involves the reaction model and the Arrhenius equation. The reaction kinetics in this study were calculated on the basis of the Coats-Redfern equation approximated by a first-order reaction, as

Table 1. Formulation of EPDM compound.

\begin{tabular}{lccc}
\hline \multirow{2}{*}{ Materials } & \multicolumn{3}{c}{ Code } \\
& \multicolumn{1}{c}{ part per hundred resin $(\mathrm{phr})$} \\
\cline { 2 - 4 } & MB & MBTM & TB \\
\hline EPDM & 60 & 60 & 60 \\
CB N220 & 60 & 60 & 60 \\
ZnO & 5 & 5 & 5 \\
Stearic acid & 1 & 1 & 1 \\
TMQ & 1 & 1 & 1 \\
Paraffinic wax & 0.5 & 0.5 & 0.5 \\
Paraffinic oil & 5 & 5 & 5 \\
MBTS & 1.5 & 1 & - \\
TBBS & - & - & 1.5 \\
TMTD & - & 0.5 & - \\
Sulphur & 0.6 & 0.6 & 0.6 \\
\hline
\end{tabular}

Table 2. Formulation of NR compound.

\begin{tabular}{cccc}
\hline \multirow{2}{*}{ Materials } & \multicolumn{3}{c}{ Code } \\
& \multicolumn{3}{c}{ part per hundred resin $(\mathrm{phr})$} \\
\cline { 2 - 4 } & MB & MBTM & TB \\
\hline SIR 20 & 40 & 40 & 40 \\
N 220 & 20 & 20 & 20 \\
MAH & 3 & 3 & 3 \\
DCP & 0.4 & 0.4 & 0.4 \\
\hline
\end{tabular}


in a study by a previous researcher (Kahrizsangi \& Abbasi, 2008; Mayasari \& Yuniari, 2016). The rate of degradation can be described in the equation:

$\frac{d x}{d t}=k(T) f(x)$

where

$x=\frac{w_{0}-w_{t}}{w_{0}-w_{f}}$

$k=A \exp \left(-\frac{E}{R T}\right)$

$f(x)=1-x$

For constant heating rate, $\beta=\frac{d T}{d t}$, equation (1) can be arranged:

$\frac{d x}{d T}=\frac{A}{\beta}(1-x) \exp \left(-\frac{E}{R T}\right)$

An integration from Eq. (5) leads to the equation:

$\ln \left[-\frac{\ln (1-x)}{T^{2}}\right]=\ln \left[\frac{A R}{\beta E}\left(1-\frac{2 R T}{E}\right)\right]-\frac{E}{R T}$

$\frac{2 R T}{E}$ could be neglected because the value is almost 1, Eq. (6) can be expressed in equation:

For $n=1$

$\ln \left[-\frac{\ln (1-x)}{T^{2}}\right]=\ln \left(\frac{A R}{\beta E}\right)-\frac{E}{R T}$

Where $A$ is the pre-exponential factor, $x$ is the degree of conversion, $k(T)$ is the rate constant, $E$ is the apparent activation energy, $w_{t}$ is the sample weight at $t, w_{0}$ is the initial sample weight, $w_{f}$ is the final sample weight, $R$ is the gas constant, $8,314 \mathrm{~J} /(\mathrm{mol} . \mathrm{K}), T$ is the absolute temperature, $\mathrm{K}$.

\section{RESULTS AND DISCUSSION Thermal Degradation}

From the thermogravimetric analysis performed, the thermogravimetric (TG) curves are shown in Figure 1 and the derivative thermogravimetric (DTG) curves are shown in Figure 2. The thermogravimetric curves show the mass decomposed versus temperature. TG and DTG curves provide information about the extent and the nature of degradation.

Figure 1 shows that the TG curves have similar regions for all of the blends. It happens because the formulation of NR/EPDM blends are constant.
All of the NR/EPDM blends with MAH compatibilizers have a good thermal resistance with quite large remaining mass at $600{ }^{\circ} \mathrm{C}(39.89 \%)$. The blend with good compatibility results good thermal resistance (Komalan et al., 2008; Alam et al., 2014). The anhydride groups on the MAH will give stronger bonding and can enhance the interfacial interaction between rubber-rubber and rubber-filler. This strong interaction is essential to achieve a good thermal stability.

The derivative thermogravimetric curve in Figure 2 shows that the degradation occurs in two stage, this is in accordance with the study by Nabil et al. (2014). There are two sharps peak that indicates the temperature when the highest mass degradation occurs. The DTG curves show that MBTS and combination of MBTS and TMTD almost have the same characteristics, while TBBS provides a lower peak. Initial minor mass degradation is seen at temperatures up to $140{ }^{\circ} \mathrm{C}$ which can be attributed to the moisture content's evaporation.Water dehydration occurs and the volatile material is released, such as MAH (boiling point $200{ }^{\circ} \mathrm{C}$ ). The temperature in first

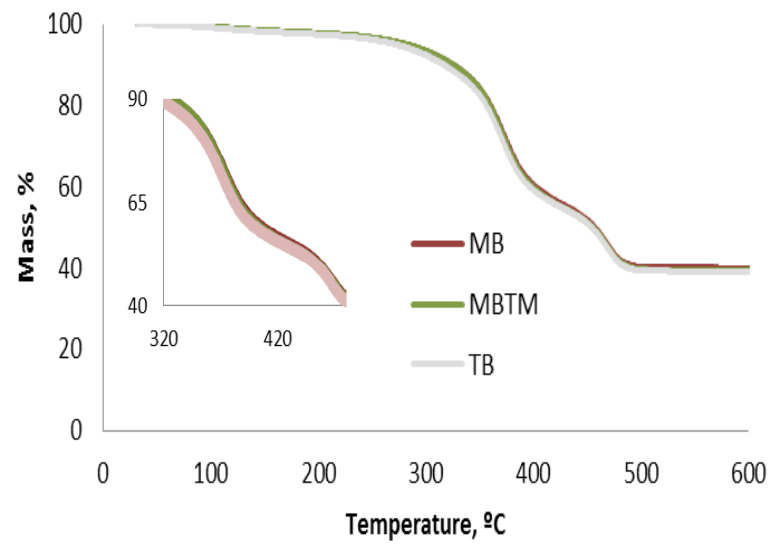

Figure 1. Thermogravimetric (TG) curves of NR/ EPDM blends.

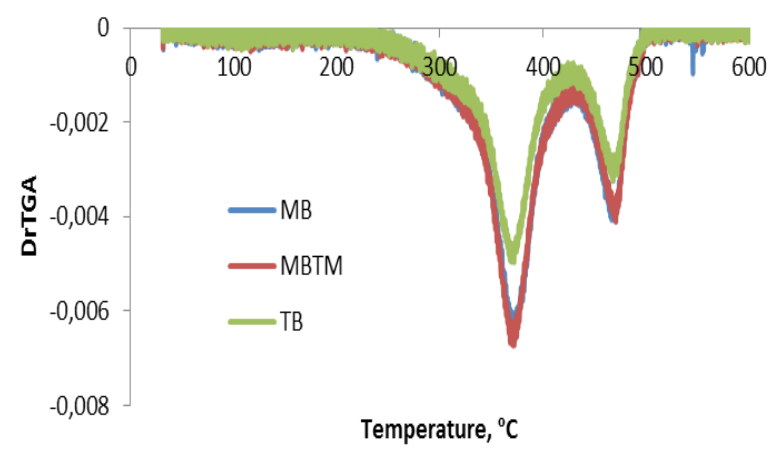

Figure 2. The derivative thermogravimetric curves of the NR/EPDM blends. 
degradation stage is not significantly different for overall blends, at around $220{ }^{\circ} \mathrm{C}$ and was completed at around $420^{\circ} \mathrm{C}$ with the mass residue is $70.96-73.30 \%$. The first stage is the releasing of the nonrubber materials step, such as processing oil, MBTS, TMTD, TMQ, stearic acid (boiling point $302{ }^{\circ} \mathrm{C}, 305{ }^{\circ} \mathrm{C}, 307{ }^{\circ} \mathrm{C}, 320{ }^{\circ} \mathrm{C}, 361{ }^{\circ} \mathrm{C}$ ) and the oxidation of NR. The degradation of the NR molecules happen because of the presence of the oxidized structure and also because of the depletion of sulphidic crosslink in NR (Nabil et al., 2014).

The second stage occurs at $420-520^{\circ} \mathrm{C}$. The chain scission of EPDM chain happens in this stage. The formation of free radicals from the oxidation reaction will attack the double bond on the ENB in the EPDM chain. Moreover, a high ENB (ethylidene-2-norbornene) content was used in this study $(8.7 \%)$. The greater the ENB content, the easier the EPDM is oxidized (Ning et al., 2014). After stage II is complete, the char residue is remaining (38.86-39.89\%). In this study, the NR/EPDM blend was degraded perfectly at temperatures of about $519-522^{\circ} \mathrm{C}$. The degradation stages of NR/EPDM blends are shown in Table 3.

Table 3 shows that the variation of accelerators gives no significant difference in char residue, because the amount of char residue mostly depends on the amount and type of filler. Table 3 shows that MBTS provide better thermal resistance with higher char residue, then the combination of MBTS and TMTD, then TBBS. It may happen because MBTS is a moderate-speed accelerator, so it needs longer time in vulcanization process and provides higher rubber chain. The higher crosslink density can improve the thermal stability of the polymer. This is accordance with the study by Azar \& Sen (2016) which found that the moderate-speed accelerator cause more stable monosulphide and disulphide crosslink and give better aging resistance than fast-speed accelerator.

\section{Kinetics Analysis}

The kinetics parameter of the degradation of NR/EPDM blends can be calculated from data of thermogravimetric result. The kinetic parameters need to be studied to obtain the optimal design and prediction the lifetime of the product. Activation energy is used to determine the energy needed to break down the rubber bond. From Equation (7), the linear plot of $\ln \left[-\frac{\ln (1-x)}{T^{2}}\right]$ versus $1 /$ T allowed us to obtain the apparent activation energy from the slope $-E / R$ and obtain the pre-exponential factor from an intercept. The first order is being the assumption in this study. Because of the slow heating rate and small sample size, the first order reaction is used as an assumption in this study. Plot $\ln \left[-\frac{\ln (1-x)}{T^{2}}\right]$ versus $1 / \mathrm{T}$ are shown in Figure 3.

The values of activation energy and the preexponential factor from Figure 3 are shown in Table 4 . The NR/EPDM blends require activation energy of 42.239 to $43.903 \mathrm{~kJ} / \mathrm{mol}$ for stages I and 68.096 to $68.617 \mathrm{~kJ} / \mathrm{mol}$ for stage II. From Figure 3 , it is known that the correlation coefficient $\left(\mathrm{R}^{2}\right)$ is approaching 1 for stage I and II. This indicates that each stage can be approached using first order. Table 4 shows that MBTS give the highest activation energy in stage I, both used single and binary. But, MBTS provide the lowest activation energy in stage II. In the opposite, TBBS provide the lowest activation energy in stage I and the highest activation energy in stage II. Activation energy is the energy needed to break the chemical bonds of the composite. This indicates that MBTS as accelerator that can increase the speed of vulcanization and permit vulcanization to proceed at lower temperature with greater efficiency is well crosslinked in NR molecules than EPDM, in stage I. In the other hand, TBBS is more cross-linked on EPDM molecules than NR, requiring large activation energies in stage II. The high activation energy in the blends containing high crosslinking (Nabil et al., 2014). Combination of MBTS and TMTD give the highest activation energy of NR/

Table 3. The degradation stage of NR/EPDM blends.

\begin{tabular}{cccccc}
\hline \multirow{2}{*}{ Code } & \multicolumn{2}{c}{ Stage I } & \multicolumn{2}{c}{ Stage II } & \multirow{2}{*}{$\begin{array}{c}\text { Total activation } \\
\text { energy }(\mathrm{kJ} / \mathrm{mol})\end{array}$} \\
\cline { 2 - 5 } & $\begin{array}{c}\text { Activation } \\
\text { energy }\end{array}$ & $\begin{array}{c}\text { Pre-exponential } \\
\text { factor (A), }\left(\mathrm{min}^{-1}\right)\end{array}$ & $\begin{array}{c}\text { Activation } \\
\text { energy }\end{array}$ & $\begin{array}{c}\text { Pre-exponential } \\
\text { factor (A), }\left(\mathrm{min}^{-1}\right)\end{array}$ & \\
\hline MB & 43.903 & 0.00461 & 68.096 & 0.295 & 111.999 \\
MBTM & 43.895 & 0.00460 & 68.340 & 0.304 & 112.236 \\
TB & 42.239 & 0.00362 & 68.617 & 0.316 & 110.856 \\
\hline
\end{tabular}


Table 4. Kinetics parameter of NR/EPDM blends.

\begin{tabular}{ccccccc}
\hline & \multicolumn{3}{c}{ Stage I } & \multicolumn{2}{c}{ Stage II } & Char \\
\cline { 2 - 5 } Code & Temp., ${ }^{\circ} \mathrm{C}$ & $\begin{array}{c}\text { Peak } \\
\text { temp., }{ }^{\circ} \mathrm{C}\end{array}$ & $\begin{array}{c}\text { Mass at } \\
\text { the end of } \\
\text { stage I, \% }\end{array}$ & Temp., ${ }^{\circ} \mathrm{C}$ & $\begin{array}{c}\text { Peak } \\
\text { temp., }{ }^{\circ} \mathrm{C}\end{array}$ & $\begin{array}{c}\text { residue, } \\
\%\end{array}$ \\
\hline MB & $224-419$ & 372.55 & 72.60 & $419-522$ & 470.42 & 39.89 \\
MBTM & $219-421$ & 370.64 & 73.30 & $421-520$ & 470.52 & 39.23 \\
TB & $220-418$ & 371.84 & 70.96 & $418-519$ & 468.02 & 38.86 \\
\hline
\end{tabular}

EPDM blends. TBBS give lower activation energy than MBTS. The use of biner accelerator gives better thermal resistance than the single accelerator. This could happen because biner accelerator shows a synergistic activity on the NR/EPDM blends, that shown from higher crosslinking than single accelerator (Indrajati \& Sholeh, 2014).

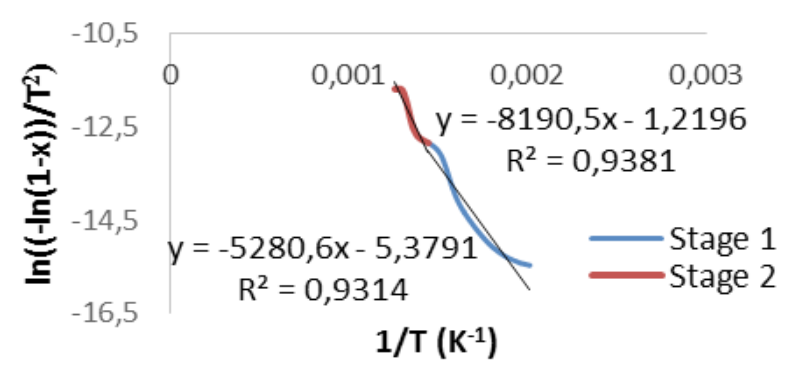

(a)

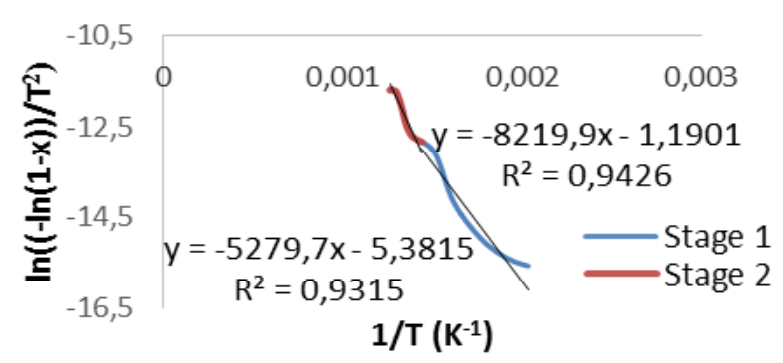

(b)

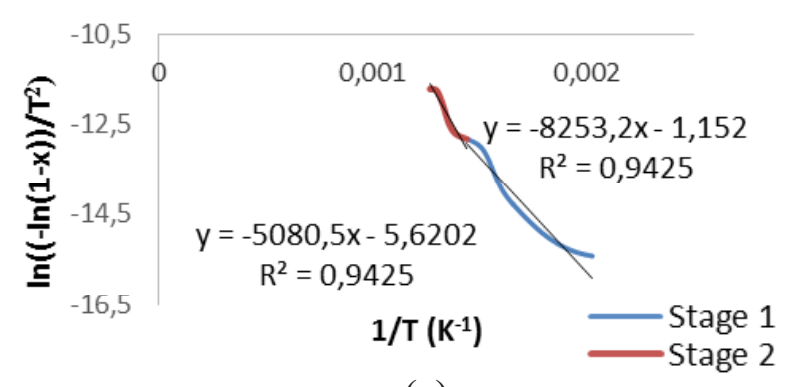

(c)

Figure 3. Plot $\ln =\left[-\frac{\ln (1-x)}{T^{2}}\right] \quad$ versus $1 / \mathrm{T}$ of NR/ EPDM blend (a) MBTS-blend, (b) MBTS/TMTDblend, (c) TBBS-blend.

\section{CONCLUSIONS}

From the research that has been done, it is known the degradation of NR/EPDM blends occurs in two stages. The first stage occurs at around $220-420^{\circ} \mathrm{C}$ and the second stage occurs at $420-520$ ${ }^{\circ} \mathrm{C}$ with char residue $39.89 \%, 39.23 \%$, and $38.86 \%$ for MBTS, MBTS/TMTD, and TBBS-blends. Combination of MBTS and TMTD give higher energy activation $(112.236 \mathrm{~kJ} / \mathrm{mol})$, followed by MBTS-blend (111.999 kJ/mol), and TBBS-blend $(110.856 \mathrm{~kJ} / \mathrm{mol})$. The accelerator type affects the activation energy on the degradation of the blend. Thus, the blending of NR/EPDM using the combination of MBTS/TMTD with MAH as a compatibilizer is proper for NR/EPDM blends to get a good thermal resistance. Further study is required to obtain a higher correlation coefficient by fitted another reaction model.

\section{ACKNOWLEDGEMENT}

The authors would like to acknowledge the Centre of Leather, Rubber, and Plastics, Ministry of Industry, Indonesia for financial support.

\section{REFERENCES}

Alam, N., Mandal, S. K., Roy, K., \& Chandra, S. (2014). Synergism of novel thiuram disulfide and dibenzothiazyl disulfide in the vulcanization of natural rubber: curing, mechanical and aging resistance properties. International Journal of Industrial Chemistry, 5(8), 1-11, https://doi.org/10.1007/s40090-014-0008-6

Alipour, A., Naderi, G., Bakhshandeh, G. R., Vali, H., \& Shokoohi, S. (2011). Elastomer nanocomposites based on NR/EPDM/Organoclay: morphology and properties. International Polymer Processing, $26,48-55$.

Azar, F. A. N., \& Sen, M. (2016). Effects of accelerator type on stress relaxation behavior and network structure of aged natural rubber/chloroprene rubber vulcanizates. Journal of Elastomers and Plastics, 1-16, https://doi.org/10.1177/0095244316663268 
Indrajati, I. N., \& Sholeh, M. (2014). Pengaruh rasio MBTS/ZDEC pada campuran karet alam dan etilen propilen diena yang dibuat dengan teknik kontrol migrasi curatives. Majalah Kulit, Karet, dan Plastik, 30(1), 43-52, https://doi.org/10.20543/mkkp.v30i1.124

Ismail,H., \& Mathialagan, M.(2012). Compatibilization of bentonite filled ethylene-propylene-diene monomer composites: effect of maleic anhydride grafted EPDM. Journal of Applied Polymer Science, 1-8, https://doi.org/10.1002/app.37606

Kahrizsangi, R. E., \& Abbasi, M. H. (2008). Evaluation of reliability of Coats-Redfern method for kinetic analysis of non-isothermal TGA. Transactions of Nonferrous Metals Society of China, 18, 2-6.

Komalan, C., George, E. K., Varghese, K. T., Mathew, V. S., \& Thomas, S. (2008). Thermogravimetric and wide angle X-ray diffraction analysis of thermoplastic elastomers from nylon copolymer and EPDM rubber. Polymer Degradation and Stability, 93(12), 2104-2112, https://doi.org/10.1016/j.polymdegradstab.2008.08.011

Mayasari, H. E., Setyorini, I., \& Yuniari, A. (2017). The blending of EPDM/NR with maleic anhydride as compatibilizer: comparing the effect of accelerators on cure characteristic and mechanical properties. Presented at International Conference on Science and Technology on July11th, 2017.

Mayasari, H. E., \& Yuniari, A. (2016). Karakteristik termogravimetri dan kinetika dekomposisi EPDM dengan bahan pengisi carbon black. Majalah Kulit, Karet, dan Plastik, 32(2), 125-134, https://doi.org/10.20543/mkkp.v32i2.1591

Nabil, H., Ismail, H., \& Azura, A. R. (2013). Compounding, mechanical and morphological properties of carbon-black-filled natural rubber/ recycled ethylene-propylene-diene-monomer (NR/R-EPDM) blends. Polymer Testing, 32(2), 385-393.

Nabil, H., Ismail, H., \& Azura, A. R. (2014). Optimisation of accelerators and vulcanising systems on thermal stability of natural rubber/recycled ethylene-propylene-diene-monomer blends. Materials and Design, 53, 651-661, https://doi.org/10.1016/j.matdes.2013.06.078
Ning, N., Ma, Q., Zhang, Y., Zhang, L., \& Wu, H. (2014). Enhanced thermo-oxidative aging resistance of EPDM at high temperature by using synergistic antioxidants. Polymer Degradation and Stability, $102,1-8$, https://doi.org/10.1016/j.polymdegradstab.2014.01.037

Pasbakhsh, P., Ismail, H., Fauzi, M. N. A., \& Bakar, A. A. (2009). Influence of maleic anhydride grafted ethylene propylene diene monomer (MAH-gEPDM) on the properties ofEPDM nanocomposites reinforced by halloysite nanotubes. Polymer Testing, 28(5), 548-559, https://doi.org/10.1016/j.polymertesting.2009.04.004

Sae-oui, P., \& Sirisinha, C. (2007). Influence of accelerator type on properties of NR/EPDM blends. Polymer Testing, 26, 1062-1067, http://doi.org/10.1016/j.polymertesting.2007.07.004

Sahakaro, K., Pongpaiboon, C., \& Nakason, C. (2008). Improved mechanical properties of NR/EPDM blends by controlling the migration of curative and filler via reactive processing technique. Journal of Applied Polymer Science, 111, 2035-2043, http://doi.org/10.1002/app.29193

Samarz, S., Budinski-simendic, J., Markovic, G., \& Marinovic, M. (2013). Composites based on carbon black reinforced NBR/EPDM rubber blends. Journal Composites, 45, 333-340, https://doi.org/10.1016/j.compositesb.2012.05.020

Tavakoli, M., Katbab, A. A., \& Nazockdast, H. (2011). Effectiveness of maleic anhydride grafted EPDM rubber (EPDM-g-MAH) as compatibilizer in NR/organoclay nanocomposites prepared by melt compounding. Journal of Macromolecular Science, 50, 1270-1284, https://doi.org/10.1080/00222348.2010.507439 